\title{
CURSOS DE FORMAÇÃO PEDAGÓGICA PARA DOCENTES GRADUADOS NÃO LICENCIADOS DOS INSTITUTOS FEDERAIS
}

\author{
Marcelo Vera Cruz Diniz ${ }^{1}$
}

Bráulio José de Oliveira Pereira²

\begin{abstract}
RESUMO: Tratamos aqui de uma pesquisa em andamento sobre os cursos de formação pedagógica para os docentes graduados não licenciados dos institutos federais (IF). É uma pesquisa que está sendo delineada dentro de uma abordagem qualitativa com o uso do estudo do caso como método, utilizando-se de análise documental dos projetos pedagógicos de seis cursos de licenciatura ofertados nos IF. Esta pesquisa tem por objetivo analisar as propostas de licenciatura direcionadas à formação dos profissionais do magistério da educação profissional, especificamente no que diz respeito à concepção pedagógica de ensino integrado presente em seus textos. Tal estudo justifica-se pela intenção em descrever o cenário de formação proposto pelos IF aos seus professores não licenciados. Os resultados preliminares apontam que os projetos negligenciam temas como trabalho como princípio educativo, interdisciplinaridade, contextualização e transformação da realidade social, considerados elementos orientadores em práticas pedagógico-curriculares integradoras.
\end{abstract}

Palavras-chave: Formação docente. Educação profissional. Currículo integrado.

\footnotetext{
${ }^{1}$ Doutor em Modelagem Computacional pela Faculdade de Tecnologia SENAI/CIMATEC (2017). Mestre em Bioinformática pela Universidade Estadual de Feira de Santana (2010) e Graduado em Ciências da Computação pela Faculdade Ruy Barbosa (2006). Atualmente é Professor Efetivo do Instituto Federal de Educação, Ciência e Tecnologia da Bahia, lotado no Campus Salvador. Docente do Programa de PósGraduação em Educação Profissional e Tecnológica - ProfEPT (Mestrado), atua no curso de Pósgraduação em Educação Profissional, Científica e Tecnológica - EPCT (Especialização), no curso de Pósgraduação em Desenvolvimento de Aplicações e Games para Dispositivos móveis - EDSGDM (Especialização), no curso de Análise e Desenvolvimento de Sistemas - ADS (Graduação), no curso de Tecnologia em Jogos Digitais do Campus Lauro de Freitas (Graduação), nos cursos técnicos de nível médio.E-mail: marcelodiniz@ifba.edu.br

${ }^{2}$ Mestre em Educação Profissional e Tecnológica (ProfEPT) pelo Instituto Federal da Bahia. Possui graduação em Pedagogia pela Universidade do Estado da Bahia (UNEB/2009), especialização em Gestão Estratégica em Educação a Distância pelo Centro Universitário do Serviço Nacional do Comércio (SENAC) e especialização em Gestão, Supervisão e Orientação Educacional pela Universidade Cândido Mendes. Atualmente é Técnico em Assuntos Educacionais, regime estatutário, da Universidade Federal do Oeste da Bahia. E-mail: braulio.bj@hotmail.com
} 


\title{
PEDAGOGICAL TRAINING COURSES FOR UNDERTAKED GRADUATES OF FEDERAL INSTITUTES
}

\begin{abstract}
This is an ongoing research on pedagogical training courses for unlicensed graduates of federal institutes (IF). It is a research that is being delineated within a qualitative approach with the use of case study as a method, using documentary analysis of the pedagogical projects of six undergraduate $\mathrm{FI}$ courses. This research aims to analyze the proposals of undergraduate degree directed to the formation of the professionals of the professional education teachers regarding the pedagogical conception of integrated teaching present in their texts. Such study is justified by the intention to describe the formation scenario proposed by the FI to their unlicensed teachers. The preliminary results indicate that the projects neglect themes such as work as an educational principle, interdisciplinarity, contextualization and transformation of social reality, considered guiding elements in integrative pedagogical-curricular practices.
\end{abstract}

Keywords: Teacher training. Professional education. Integrated curriculum.

\section{CURSOS DE FORMACIÓN PEDAGÓGICA PARA GRADUADOS NO LICENCIADOS DE LOS INSTITUTOS FEDERALES}

RESUMEN: Esta es una investigación en curso sobre cursos de capacitación pedagógica para graduados sin licencia de institutos federales (IF). Es una investigación que se está delineando dentro de un enfoque cualitativo con el uso del estudio de casos como método, utilizando el análisis documental de los proyectos pedagógicos de seis cursos de pregrado de FI. Esta investigación tiene como objetivo analizar las propuestas de licenciatura dirigidas a la formación de los profesionales del profesorado de educación profesional en relación con la concepción pedagógica de la enseñanza integrada presente en sus textos. Tal estudio se justifica por la intención de describir el escenario de formación propuesto por la FI a sus maestros sin licencia. Los resultados preliminares indican que los proyectos descuidan temas como el trabajo como principio educativo, la interdisciplinariedad, la contextualización y la transformación de la realidad social, considerados elementos orientadores en las prácticas pedagógicas-curriculares integradoras.

Palabras clave: Formación docente. Educación profesional. Currículo integrado. 


\section{Introdução}

Com a ampliação da oferta da educação profissional no Brasil, principalmente após a homologação da lei que criou os Institutos Federais de Educação, Ciência e Tecnologia, Lei no 11.892, de 29 de dezembro de 2008 (BRASIL, 2008) houve, na mesma proporção, o crescimento dos debates em relação à formação docente para atuar na Educação Profissional e Tecnológica (EPT). Contudo, segundo Carvalho e Souza (2014), mesmo com o aumento das discussões sobre este tema, poucas são as posições conclusivas, sobretudo no que diz respeito aos modelos de formação docente e quais os saberes necessários para ministrar aulas neste campo educacional.

Acontece que, muitas vezes, ao falarmos sobre formação de professores, concentramos nossas ideias e pensamentos apenas no que se refere aos conhecimentos técnico-pedagógicos vinculados aos processos educativos e metodológicos das áreas propedêuticas (linguagens, história, geografia, matemática, física, química e biologia), em detrimento de temas das áreas específicas do ensino técnico. Não analisamos as concepções e os fundamentos teórico-metodológicos próprios da EPT, sua organicidade e, muito menos, suas estratégias didáticas.

Isto se dá, segundo Machado (2008), por falta de políticas públicas voltadas para educação profissional, ainda resquício do escamoteio histórico desta área em relação a outros níveis ou modalidades de oferta de ensino, o que gera, como uma de suas consequências, a escassez de profissionais da educação capacitados para atuar na educação profissional. Somamos a isto a pouca efetividade de marcos regulatórios que não se concretizam em ações governamentais voltadas à formação docente para o ensino técnico. A Lei no 9.394, de 20 de dezembro de 1996 (BRASIL, 1996) e o Plano Nacional de Educação (BRASIL, 2014) tratam, de forma direta ou indireta, de direcionamentos para formação de professores do ensino básico ou estabelecem normas e políticas que devem ser feitas para garantir a formação mínima dos profissionais do magistério, porém sem resultados consistentes. Basta vermos, por exemplo, a Tabela 1 abaixo, na qual se demonstra o número de professores da EPT que no ano de 2017 ainda não eram licenciados.

Neste cenário, a maior parte dos docentes não licenciados é composta por professores das áreas técnicas, geralmente bacharéis e tecnólogos, que não são 
alcançados por políticas de formação pedagógica ou, em outros casos, por estigma à profissão docente, não consideram relevante a licenciatura para atuar nesta área.

Tabela 1 - Formação acadêmica dos docentes na EPT no Brasil

\begin{tabular}{ccc}
\hline $\begin{array}{c}\text { Nível de escolaridade e formação acadêmica dos } \\
\text { docentes da ETP no Brasil }\end{array}$ & $\begin{array}{c}\text { Número de } \\
\text { docentes }\end{array}$ & Porcentagem \\
\hline Fundamental & 132 & $0,1 \%$ \\
Ensino Médio & 9787 & $7,7 \%$ \\
Graduados com licenciatura & 75.691 & $59,5 \%$ \\
Graduados sem licenciatura & 41.445 & $32,7 \%$ \\
TOTAL & 127.055 & $100 \%$ \\
\hline
\end{tabular}

Fonte: Adaptado da Sinopse Estatística da Educação Básica 2017 (INEP, 2018)

Como pode-se notar na Tabela 1, os dados expostos mostram que a educação profissional no Brasil contava, naquele ano, com um quadro de $32,7 \%$ dos profissionais do magistério sem a formação pedagógica necessária para atuar na educação profissional técnica de nível médio, isto não incluindo os docentes sem graduação.

Como contraponto e tentativa de se alinhar às exigências legais, os Institutos Federais (IF) propõem cursos de formação pedagógica direcionados aos professores graduados sem licenciatura, com o objetivo de sanar as deficiências pedagógicas deste público. Assim, são planejados cursos de formação pedagógica para professores graduados não licenciados com tempo reduzido, nos quais se delineiam perfis docentes de forma geral, em graduações emergenciais ou especiais para EPT.

Com isso, ao abordamos sobre formação dos profissionais do magistério, não menosprezando as exigências legais, planos nacionais ou políticas públicas de oferta de cursos de licenciatura especiais, precisamos nos questionar também sobre a qualidade de sua profissionalização. Oliveira e Nogueira (2016) argumentam que uma educação de qualidade social está intimamente ligada à formação do profissional do magistério, não o limitando ao mestre que trabalha como os processos de ensino dos conteúdos para o estudante aprender, mas o elevando a sujeito histórico e que compreende o processo formativo nas relações entre trabalho e educação, sempre numa perspectiva emancipadora.

Segundo Moura (2008, p.30), no processo educativo próprio da EPT, "o professor deve assumir outra atitude, forjada a partir de outro tipo de formação, que deve ser crítica, reflexiva e orientada à responsabilidade social". Nestes termos, sua 
formação deve se alinhar a uma perspectiva de educação profissional que trabalhe com a formação integral do ser humano, não o reduzindo aos interesses de mercado, sendo esta a perspectiva de formação docente para EPT.

Ademais, a nossa proposta é apontar como estes cursos tratam a formação dos professores no que diz respeito ao alinhamento da concepção de ensino integrado, entendido aqui não só como uma das modalidades de oferta da EPT (união do ensino médio com o ensino profissionalizante), mas também como uma perspectiva de ensino consonante com a educação politécnica, tendo como referência os aportes teóricometodológicos sob os quais foram concebidos a educação de cunho progressista ou omnilateral (educação marxista), bem como sua organização curricular, perfil do egresso proposto e prática profissional docente por ela preconizada.

Dito isso, cabe-nos aqui alguns questionamentos: julgando que há especificidades no trato com a EPT, a exemplo do ensino integrado ofertado pelos IF, sob qual concepção pedagógica são estruturados cursos de formação para professores graduados não licenciados ofertados pelos institutos? Eles preparam os professores para atuarem numa perspectiva crítica e voltada para a formação politécnica, visando à formação integral dos estudantes?

Nosso trabalho, portanto, objetiva analisar os projetos dos cursos de formação pedagógica dos IF oferecidos aos docentes graduados não licenciados, no que diz respeito à concepção pedagógica de ensino integrado de cunho politécnico/ omnilateral direcionada à formação dos profissionais do magistério para atuarem na educação técnica e tecnológica.

Com isso, além dessas palavras introdutórias, nosso trabalho foi estruturado da seguinte forma: inicialmente traçamos alguns aspectos históricos e políticos da formação docente na EPT no Brasil; posteriormente trataremos o currículo integrado e seus princípios orientadores; também delineamos os procedimentos e métodos que serão utilizados na pesquisa, os resultados e discussão dos dados obtidos; por fim, tecemos algumas considerações dos resultados, ainda parciais, que encontramos.

\section{Aspectos históricos e políticos da formação docente para EPT no Brasil}

Se fizermos uma análise do percurso histórico da educação profissional no Brasil, vamos perceber que até o século XIX não existia, no ensino formal ou algo 
próximo a ele, organizações ou sistemas voltados para educação profissional, a exemplo dos IF. Naquele período, o que prevalecia era a oferta da educação propedêutica para a elite, renegando aos escravos e aos pobres o acesso à instrução. Só com a chegada da Família Real, em 1809, é que foi criado o Colégio das Fábricas, primeira instituição de ensino técnico do país, marcando o início da educação profissional no Brasil (MOURA, 2008).

Entretanto, o cunho assistencialista era a primeira e principal característica das instituições de ensino profissionalizante. Seu público era composto de crianças carentes, chamadas de desafortunadas (MOURA, 2008). Deriva disso, juntamente com o trabalho manual (aquele que era feito somente por escravos), o preconceito que reverbera atualmente em torno da educação profissional, tangenciando-a em um status inferiorizado no ensino formal.

Este cenário, contudo, só se modifica com a abertura da Escola de Aprendizes e Artífices, no governo de Nilo Peçanha em 1909, que iniciou uma política governamental voltada para educação profissional, mesmo que esta política ainda fosse de cunho assistencialista (RODRIGUES; SOUZA, 2017). Com a criação desta nova escola, houve a necessidade de professores para atuarem no ensino técnico, demandando, por consequência, formação destes profissionais neste campo. Tal fato, anos depois, seria um dos motivos para a criação da Escola Normal de Artes e Ofícios Wenceslau Braz em 1917, entrando em funcionamento 2 anos depois.

A Escola Wenceslau Braz, inicialmente, apenas atendia alunos do sexo masculino, fato que só posteriormente, em 1921, começa a admitir matrículas femininas, voltadas para formação de professoras na área de Prendas e Economia Doméstica, cursos que predominavam na escola desde então. No Governo Vargas, entretanto, esses cursos femininos foram o motivo do fechamento da escola, argumentando-se que a instituição não cumpria o objetivo principal para o qual fora criada: formação de mestres para as oficinas. Posteriormente, foi criada a Escola Técnica Nacional, que tinha como objetivo formar artífices, mestre e técnicos por conta do grande crescimento industrial da época, como determinava a Lei Orgânica do Ensino Industrial de 1942, conhecida também como Reforma Capanema.

Entre outras coisas, segundo Rodrigues e Souza (2017), esta reforma, instituía o ensino pedagógico para o magistério, com abrangência dos cursos de Didática e 
Administração do Ensino Industrial. Santos (2016), porém, constata que a Lei Orgânica do Ensino Industrial de 1942, que pretendia uma formação voltada para as competências pedagógicas para os professores do ensino técnico era apenas um instrumento legal, já que não houve ações efetivas daquilo que a nova norma colocava.

Além disso, outro fato relevante para formação de docentes para educação profissional foi o acordo de cooperação educacional entre estadunidenses e brasileiros, celebrado em 1946, denominado de Comissão Brasileiro-Americana de Educação Industrial (CBAI). Este acordo, em 1947, promovia, entre outras atividades, o primeiro curso de aperfeiçoamento de professores e técnicos do ensino industrial. $\mathrm{O}$ acordo foi prorrogado por repetidas vezes, modificando, inclusive, as intervenções da comissão voltadas incialmente para os aspectos mais burocráticos e administrativos que passaram para uma atuação de caráter mais técnico-pedagógico, culminando, inclusive, na criação do Centro de Pesquisa e Treinamento de Professores. O centro, segundo Rodrigues e Souza (2017, p.627) "ofereceria cursos de aperfeiçoamento para docentes de diferentes especialidades e oriundo de diversas localidades do país".

No ano de 1960, já sob a égide da primeira Lei de Diretrizes e Bases da Educação Nacional, Lei no 4.024/61, foram criados regulamentos para atuação docente no país. Esta Lei, segundo Santos (2016), estabelecia que a formação dos professores para o ensino médio deveria ser feita em faculdades e as do ensino médio técnico em cursos especiais para o magistério no ensino profissionalizante. A Lei no 4.024/61 confirmava, assim, o que já era recorrente na educação brasileira historicamente: a dualidade na oferta de ensino, caracterizada pela separação entre a educação profissional e propedêutica, repetindo-se a mesma lógica na formação dos profissionais do magistério. Vejamos o que dizem Rodrigues e Souza (2017, p. 627).

Dois aspectos são merecedores de destaque com relação a esse artigo da LDB de 1961. O primeiro, diz respeito à dualidade na formação de professores, haja vista que esta estabelece locais de formação diferentes para professores de um mesmo nível de ensino. Dessa forma, pela via legal, separavam-se os espaços destinados à formação de professores. Na forma da Lei, o Ensino Médio propedêutico e o Ensino Técnico são tratados de forma distinta e independentes, como se não fossem ambos pertencentes ao mesmo nível. 0 segundo destaque que damos àquele artigo diz respeito à adjetivação dada a esses cursos: eram qualificados como "especiais". O adjetivo "especial", 
empregado pela LDB, denuncia a condição de transitoriedade das propostas de formação de professores para a Educação Profissional.

Posteriormente, esta perspectiva colocada pela Lei no 4.024/61 deu subsídios para publicação do Decreto-Lei no 616/69, que criou o Centro Nacional de Aperfeiçoamento de Pessoal para Formação Profissional. O centro durou até 1987, com o objetivo de formar, preparar, e aperfeiçoar os profissionais do magistério.

Logo após o Decreto no 616/69, criou-se em 1970 a Portaria Ministerial 339/70 os cursos emergenciais, denominados "Esquemas I e II" (RODRIGUES; SOUZA, 2017, p. 629), sendo que o primeiro voltava-se para a formação de professores portadores de diploma de nível superior, o segundo, por sua vez, era voltado para diplomados em nível técnico.

De acordo com Santos (2016), os Esquemas I e II já eram um ensaio político e regulamentar que preparava o terreno para a Lei no 5.692/71 e, com ela, a obrigatoriedade de que o ensino médio profissionalizante fosse ofertado em todas as escolas do Brasil, fato que demandaria professores para atuar no ensino técnico. Este era o objetivo da Portaria Ministerial 339/70.

Com a Lei no 9.394/96 não houve avanços significativos quanto à formação do magistério para a EPT, pois não regulamentou temas relacionados à preparação dos docentes do ensino técnico, fato que só se consolidaria com a Resolução CNE/CP $\mathrm{n}$ o 01, de 18 de Fevereiro de 2002 (BRASIL, 2002) e, posteriormente, com Resolução CNE/CP no 02, de 01 de julho de 2015 (BRASIL, 2015) que define as Diretrizes Curriculares Nacionais para a formação inicial em nível superior e para a formação continuada dos profissionais do magistério no Brasil.

Outro fato importante que comprova a indiferença das políticas públicas e normativas relacionadas à formação docente para EPT foi o Decreto no 2.208, de 17 de abril de 1997, já revogado, que não só modificava a oferta do ensino profissional no Brasil, mas também condicionava a formação de professores para a EPT à experiência em serviço nas áreas em que ele era formado, negligenciando qualquer tipo de preparo teórico-pedagógico ou conhecimento educacional para tal. Segundo o Art. 9o desse Decreto:

As disciplinas do currículo do ensino técnico serão ministradas por professores, instrutores e monitores selecionados, principalmente, em função de sua experiência profissional, que deverão ser preparados para o 
magistério, previamente ou em serviço, através de cursos regulares de licenciatura ou de programas especiais de formação pedagógica (BRASIL, 1997, s.p.).

Este Decreto foi revogado no Governo Lula, substituído pelo Decreto no 5154/04 e, posteriormente, com a promulgação da Lei no 11.195/05 que expandiu a Rede Federal de Educação Profissional e Tecnológica e, em 2015, com vigência das novas diretrizes de formação docente e do Plano Nacional de Educação (BRASIL, 2014). Embora tenham ocorrido mudanças em marcos regulatórios e políticas nacionais de educação formal, não houve mudanças consistentes no desenvolvimento da formação docente para EPT, persistindo formações diferenciadas, aligeiradas e de má qualidade para este âmbito educacional.

\section{O currículo integrado e seus princípios orientadores}

O currículo integrado é uma forma de organização pedagógica e institucional que combina ou estabelece interrelações entre prática e teoria (ARAÚJO; FRIGOTTO, 2015; RAMOS, 2005). Entretanto, para além desta concepção, uma proposta curricular integradora deve incluir outras características, tais como: questões culturais, o cotidiano de um determinado contexto histórico e social, as interações entre as diversas áreas e saberes e do próprio trabalho e sua relação com educação, para que se possa entender e agir sobre a realidade social dos sujeitos envolvidos nos processos educativos.

O que nos permite entender o currículo integrado, no que diz respeito aos seus fundamentos, está na Teoria de Gramsci (1982), especificamente no texto que discute a organização escolar e da cultura, no qual ele retrata não só como era a escola italiana na época em que viveu, mas também propõe um modelo de organização escolar e sistema educativo formal que atualmente é base para a educação integrada.

Observamos, com isso, nas narrativas de Gramsci (1982, p.117) que, geralmente, as atividades mais complexas da civilização moderna e as "ciências mesclaram-se de tal modo à vida que toda atividade prática tende a criar uma escola para os próprios dirigentes e especialistas." Este fato fez surgir, segundo o autor, um sistema diferenciado de escolas particulares e com diferentes níveis ou ramos profissionais, caracterizadas por sua desorganização e sem princípios claros ou 
precisos, o que resultou, por um lado, na divisão fundamental entre escola clássica (ensino propedêutico) para os intelectuais e classe dominante e, por outro, em escolas profissionais para os estratos sociais marginalizados.

Santomé (1998, p.10), quando trata das origens desta proposta teóricometodológica educacional integradora, relata que este movimento pedagógico nasce de reivindicações "progressistas de grupos ideológicos e políticos que lutavam por uma maior democratização da sociedade". Vinculados ao sindicalismo, estes grupos, eram contra as políticas trabalhistas e os novos ajustamentos provocados pelos princípios tayloristas e da administração científica, cujos modelos educacionais sofriam influência não só nos sistemas, mas também nas pedagogias didáticas.

Segundo Santomé (1998), todas as alterações que ocorreram no funcionamento do sistema de produção não só dispôs a um maior acúmulo de capitais e dos meios de produção, mas também diminuía o custo da mão-de-obra. A resultante desta nova modelagem econômica acentuou-se na estratificação social laborativa, pois, uma vez que o trabalhador não compreendia, em sua totalidade, os processos de produção de qualquer mercadoria ou produto, consequentemente não o permitia usufruir daquilo que ele próprio produzia, como acontecia no trabalho artesanal.

E mais: todos esses processos de desqualificação e fragmentação de atividades ocorridas dentro das fábricas e de sua distribuição acabaram por refletir nos sistemas educacionais (SANTOMÉ, 1998). Resumidamente, o que ocorria era uma espécie de atomização dos conhecimentos escolares em disciplinas fechadas semelhantes aos modelos produtivos, nos quais os trabalhadores só tinham acesso a uma parte da produção em diferentes setores. Privados dos conhecimentos necessários à vida moderna e, consequentemente, do trabalho, não tinham poder de escolha em nenhum dos casos.

Ramos (2009) também coloca que a proposta de currículo integrado define as finalidades da educação escolar ligada à formação humana, desta vez em um viés politécnico e omnilateral. Segundo a autora, "as aprendizagens escolares devem possibilitar à classe trabalhadora a compreensão da realidade para além de sua aparência e, deste modo, o desenvolvimento de condições para transformá-la em benefício de suas necessidades de classe" (RAMOS, 2009, p.115). 
A proposta, assim, interrelaciona-se às características como formação geral, formação técnica e formação política, tendo o trabalho como princípio educativo, considerando-o como "eixo epistemológico e ético-político de organização curricular" (RAMOS, 2009, p. 115). Somam-se ao trabalho, mais dois outros eixos que devem ser considerados no currículo integrado, a saber: a ciência e a cultura.

Primeiramente, o trabalho, para Ramos (2009), é entendido como ação especificamente humana no qual os indivíduos produzem sua vida, denominado de sentido ontológico. A ciência, por sua vez, representa os conhecimentos produzidos e legitimados socialmente no decorrer da história. Já a cultura, em síntese, diz respeito às diferentes formas de criação da sociedade.

Sinteticamente, as perspectivas elencadas Gramisc (1982), Santomé (1998) e Ramos (2009), mesmo que não constituídas por ideologias ou conceitos simétricos em sua totalidade, são guiados para associar os conhecimentos escolares que, no presente momento, encontram-se quebrados em áreas do saber estanques, sem comunicação qualquer com o contexto de vida dos estudantes e o desenvolvimento da autonomia do sujeito em sua realidade.

Assim, a forma de ensino integrado que por hora aqui definimos é totalmente oposta às concepções reducionista de ensino e aprendizagem que beneficiam algumas atividades humanas em detrimento de outras, reservando geralmente aos estudantes da classe trabalhadora somente a aprendizagem de capacidades e habilidades instrumentais, colocando-os de lado suas capacidades criativas e sua autonomia política.

\begin{abstract}
A ideia de integração não caracteriza, por si, uma pedagogia que visa à transformação, já que várias são as pedagogias que propõem integrar trabalho e educação. A Pedagogia das Competências, por exemplo, tomou essa integração como uma de suas principais promessas, mas fazia isso presa à realidade dada, ou seja, o seu conteúdo pragmático lhe impunha pensar essa integração visando ao ajustamento da formação humana às demandas específicas e pontuais do mercado de trabalho, diferente da integração proposta pelo projeto hoje identificado como Ensino Médio Integrado, que compreende essa integração sendo amalgamada pela ideia de transformação da realidade social (ARAÚJO; FRIGOTTO, 2015, 77-76).
\end{abstract}

Dito isto e como forma de contrapor às concepções pedagógicas utilitaristas e pragmáticas, a partir da perspectiva de Saviani (2007) e Araújo e Frigotto (2015), 
podemos definir quatro princípios orientadores que servem como ponto de partida ou norte em prática pedagógicas integradoras, a saber: trabalho como princípio educativo, a interdisciplinaridade, a contextualização e o compromisso com a transformação social.

Em relação ao trabalho como princípio educativo refere-se, obviamente à relação entre estes dois elementos: trabalho e educação. Assim, podemos afirmar que é o caráter formativo do trabalho como ação humanizadora que desenvolve as potencialidades humanas. Ciavatta, por exemplo (2008, p. 408), coloca que o campo específico de discurso desta narrativa é o "materialismo histórico em que se parte do trabalho como produtor dos meios de vida, tanto nos aspectos materiais como culturais [...]". A provisão da existência humana, neste sentido, é feita através do agir do ser humano sobre a natureza e nesta ação ele se educa e educa o seu próximo.

O fato de buscar a produção e a reprodução de sua vida societal por meio do trabalho e luta por sua existência, o ser social cria e renova as próprias condições de sua reprodução. O trabalho é, portanto, resultado de um por teleológico que (previamente) o ser social tem ideado em sua consciência, fenômeno este que não está em sua essência presente no ser biológico dos animais (ANTUNES, 1999, p. 137, grifo do autor).

O ser humano, como ser criativo e de ideias, maneja os recursos naturais e molda as relações sociais ao seu bel-prazer, com o objetivo de prover a sua vida sem depender das vicissitudes que estes dois elementos podem trazer. A teleologia, ou seja, os objetivos, dizem respeito à capacidade humana de dominar esses meios, bem como o manejo em aprender e perpetuar os saberes adquiridos.

O outro princípio refere-se à interdisciplinaridade. Sua necessidade não só está âmbito da pesquisa (como muitos pensam), mas também nos contextos pedagógicos, por conta de ser condição humana caracterizada pelo aspecto social. É nas relações de produção humana, que o conhecimento, saberes e conteúdos culturais diversos e complexos da humanidade são construídos (FRIGOTTO, 2005).

Ademais, a interdisciplinaridade está em voga por conta da carência de utilização de múltiplos saberes ou também pela excessiva compartimentalização do conhecimento disciplinar, produto de uma tendência de fragmentação das disciplinas que se especializavam progressivamente (até dentro de seus próprios contextos) para resolver problemas com maior rapidez. 
O forte peso da cultura do positivismo, com sua ênfase na precisão e a imposição de determinadas metodologias de pesquisa e, portanto, das formas de legitimação do conhecimento favoreceram a caminhada em direções disciplinares mais reducionistas; ganhava-se nos níveis de precisão nos quais se trabalhava, mas em geral perdia-se nas questões relativas à sua relevância (SANTOMÉ, 1998, p.62).

Além disso, no que diz respeito aos aspectos pedagógicos e, especificamente, nas questões relacionadas ao ensino integrador, a interdisciplinaridade, segundo Santomé (1998), pode estruturar conceitos, contextos históricos e procedimentos, estabelecendo, pelo menos inicialmente, unidades mais genéricas e estruturas conceituais e metodológicas compartilhadas. Os sujeitos da aprendizagem, com esta nova forma de pensar os processos pedagógicos, estariam assim mais capacitados a enfrentar problemas que transcendem as disciplinas tanto no que diz respeito ao seu conteúdo como a seu método.

Quanto à importância da contextualização, podemos confirmá-la nos documentos oficiais que regulam a educação, tais como a Lei no 9.394/96 ao expor deve haver íntima relação entre a vida e ao trabalho, ou também quando esta normativa reverbera nas próprias Diretrizes Curriculares Nacionais para o Ensino Médio, no item que trata sobre a contextualização no ensino, por exemplo, no art. 7으, no parágrafo 2 , referente à organização curricular:

O currículo deve contemplar tratamento metodológico que evidencie a contextualização, a diversificação e a transdisciplinaridade ou outras formas de interação e articulação entre diferentes campos de saberes específicos, contemplando vivências práticas e vinculando a educação escolar ao mundo do trabalho e à prática social e possibilitando o aproveitamento de estudos e o reconhecimento de saberes adquiridos nas experiências pessoais, sociais e do trabalho (BRASIL, 2018, p.4).

Segundo Araújo e Frigotto (2015), a contextualização deve ser encarada como uma articulação dos conteúdos utilizados nos processos pedagógicos com o cotidiano dos estudantes, dando, por sua vez, maior ênfase aos projetos políticos dos trabalhadores e das organizações populares quando esta está dentro do âmbito do ensino integrado.

Assim, negligencia-se nas práticas educativas escolares o cenário cotidiano como ponto de partida nos processos pedagógicos, privando a realidade do estudante 
e tornando-a estranha a ele. Este, por exemplo, era o cenário de propostas pedagógicas de linhas tradicionais que tinham por base o ensino do conteúdo sem conexão, aproximação com a vida em suas mais variadas dimensões. É, como dia Freire (2005) um proposta de educação bancária, na qual o aluno é apenas receptor passivo de conteúdo

Já em relação ao último princípio, a transformação da realidade social, este relaciona-se à perspectiva de atuação dos docentes no sentido de formar pessoas que visem à mudança de sua realidade social. É nesta última vertente, a do meio social a ser modificado, que, nas relações estabelecidas pela sociedade (educação) lançam os seres humanos a atuarem conscientemente sobre o mundo, de forma que eles possam alterá-lo conforme sua necessidade. Nesta perspectiva, a concepção de educação politécnica e do ensino integrado, revela que:

[...] os pressupostos para uma emancipação humana estão presentes ontologicamente. O ser humano passa a transformar a natureza de acordo com as suas necessidades, subjugando o mundo ao seu redor de acordo com sua vontade, dentro de suas capacidades históricas, desenvolvimento da humanidade, percebido pelo decorrer da história, amplia as possibilidades concretas da escolha do ser humano, o que significa a expansão de sua liberdade. Analisando a atua sociedade capitalista, a humanidade tem a possibilidade de produzir os bem necessários à sua sobrevivência com maior facilidade relativa e ainda produzir riquezas culturais que demarcam a infinidade do desenvolvimento humano (LIMA, 2016, p. 349. grifo nosso).

Assim, é nesta proposta que se delineiam as bases do ensino integrado, pois a formação humana para esta concepção de educação busca no agir integralizador os aspectos teóricos e metodológicos de sua pedagogia. O currículo integrado, assim, tem o objetivo de promover a compreensão global do conhecimento, tendo a interdisciplinaridade como pressuposto e mecanismo de aprendizagem, a negação sumária da fragmentação curricular, usando da contextualização, como também da mudança de realidade, para o bem da coletividade.

\section{Procedimentos e métodos}

Este trabalho é fruto de uma pesquisa ainda em andamento e, como abordagem metodológica, utilizamos a pesquisa de cunho qualitativo, lançando mão do estudo de 
caso como método, por entendermos que este "é caracterizado pelo estudo exaustivo de um ou de poucos objetos, de maneira a permitir o seu conhecimento amplo e detalhado" (GIL, 2014, p.57-58).

O estudo de caso, segundo Gil (2014, p. 57-58), “é caracterizado pelo estudo exaustivo de um ou de poucos objetos, de maneira a permitir o seu conhecimento amplo e detalhado." Este método é utilizado para a pesquisa de situações da vida real, nas quais não há um limite claro entre temas ou temáticas, no qual se descreve o contexto em que será feita a investigação, explicando as variáveis que um determinado fenômeno causa. Para Yin (2005, p. 32) o estudo de caso consiste em "uma investigação empírica que investiga um fenômeno contemporâneo dentro de seu contexto da vida real, especialmente quando os limites entre o fenômeno e o contexto não estão claramente definidos."

O corpus da pesquisa é constituído por projetos de curso de formação pedagógica para docentes graduados não licenciados ofertados por Institutos Federais, sendo um Projeto do Instituto Federal do Rio Grande do Norte (IFRN) de 2016; e outros projetos, todos do ano de 2018, um do Instituto Federal da Bahia (IFBA), um do Instituto Federal Farroupilha (IFFAR); um do Instituto Federal de São Paulo (IFSP ); um do Instituto Federal do Rio Grande do Sul (IFRS); e um projeto ofertado em rede para diversos IF do Brasil, doravante denominado por Projeto Rede (REDE).

A escolha desses projetos se deu a partir de projetos de cursos de formação pedagógica na forma de graduação em licenciatura em EPT ou licenciaturas voltadas para atuação docente no ensino médio técnico que estavam cadastrados nos Sistema E-MEC, referente ao mês de fevereiro de 2019, data de acesso ao referido portal do Ministério da Educação. Dos projetos cadastrados no sistema do Ministério da Educação, somente aqueles que foram propostos ou reformulados de acordo os parâmetros da Resolução CNE/CP no 02, de 2015, fizeram parte da pesquisa.

Com o auxílio da revisão bibliográfica, fizemos o tratamento dos dados por meio da análise de conteúdo. Assim, de acordo com os princípios orientadores do ensino integrado, propostos por Araújo e Frigotto (2015) e do trabalho como categoria ontológica (RAMOS, 2009), temos as seguintes categorias de análise: o trabalho como princípio educativo, a interdisciplinaridade, a contextualização e a transformação da realidade social. 
Por fim, neste arranjo metodológico, analisaremos itens considerados importantes em um projeto pedagógico de curso, aos quais denominados de blocos de análise, uma vez que neles estão contidos nos eixos filosófico-pedagógicos e perfis dos egressos, a demarcação dos objetivos a serem alcançados, as características dos profissionais a serem formados e como atuarão nos espaços escolares a partir da formação pretendida. Assim, descrevemos se os projetos referenciam ou fazem alusões dentro de seus textos à temas considerados como princípios orientadores do ensino integrado.

\section{Resultados e discussão}

Nos projetos de curso analisados, descrevemos como cada um dos elementoschave, que pontam como princípios do ensino integrado são referenciados nos textos dos projetos de acordo com as categorias elencadas. Notamos, com isso, preliminarmente, a partir das análises feitas por categoria e bloco de análise, que há uma diversidade e uma inconstância na descrição destes princípios, quando vistos cada uma das propostas pedagógicas separadamente.

Para isso, então, resumimos, na Tabela 1, por bloco de análise, as indicações de referências por categoria analisada dos princípios elencados, de modo que possamos transcrever os dados e visualizá-los melhor, desenhando um panorama do resultado preliminar de nossa pesquisa. Pelo quadro que produzimos a partir dos resultados encontrados nas análises, percebemos que as citações e referências feitas em cada bloco analisado variam conforme são dispostas as categorias elencadas. Destacamos, por exemplo, que os projetos, em sua totalidade, não abordam os princípios orientadores do ensino integrado para a implementação de um curso de formação docente que terá como público alunos desta modalidade de oferta de educação técnica.

Ao verificarmos o tema trabalho como princípio educativo, percebemos que em nenhum dos projetos ele aparece em todos os blocos analisados. Como exemplo, podemos destacar o projeto do IFBA que não faz, de forma direta, nenhuma referência a este tema. Além disso, quando há citações que dizem respeito a ele, estas não continuam em outros blocos, denotando que os proponentes do projeto não deram 
relevância a esta temática. Isto torna-se preocupante, pois, segundo Ramos (2005, p. 114) entender

[...] a concepção de homem como ser histórico-social que age sobre a natureza para satisfazer suas necessidades e, nessa ação, produz conhecimentos como síntese da transformação da natureza humana. Assim, a história da humanidade é a história da produção da existência humana, e a história do conhecimento é a história do processo de apropriação social dos potenciais da natureza para o próprio homem, mediada pelo trabalho. Por isso o trabalho é mediação ontológica e histórica na produção de conhecimento.

Com isso, inferimos que a falta de alusões sobre este tema nos diversos itens das propostas, compromete a formação de professores que atuam na educação profissional, principalmente na postura e compreensão desses profissionais naquilo que se refere ao trabalho na formação integrada, ofertada atualmente nos IF.

Tabela 1 - Princípios do ensino integrado citados por categoria e blocos de análise.

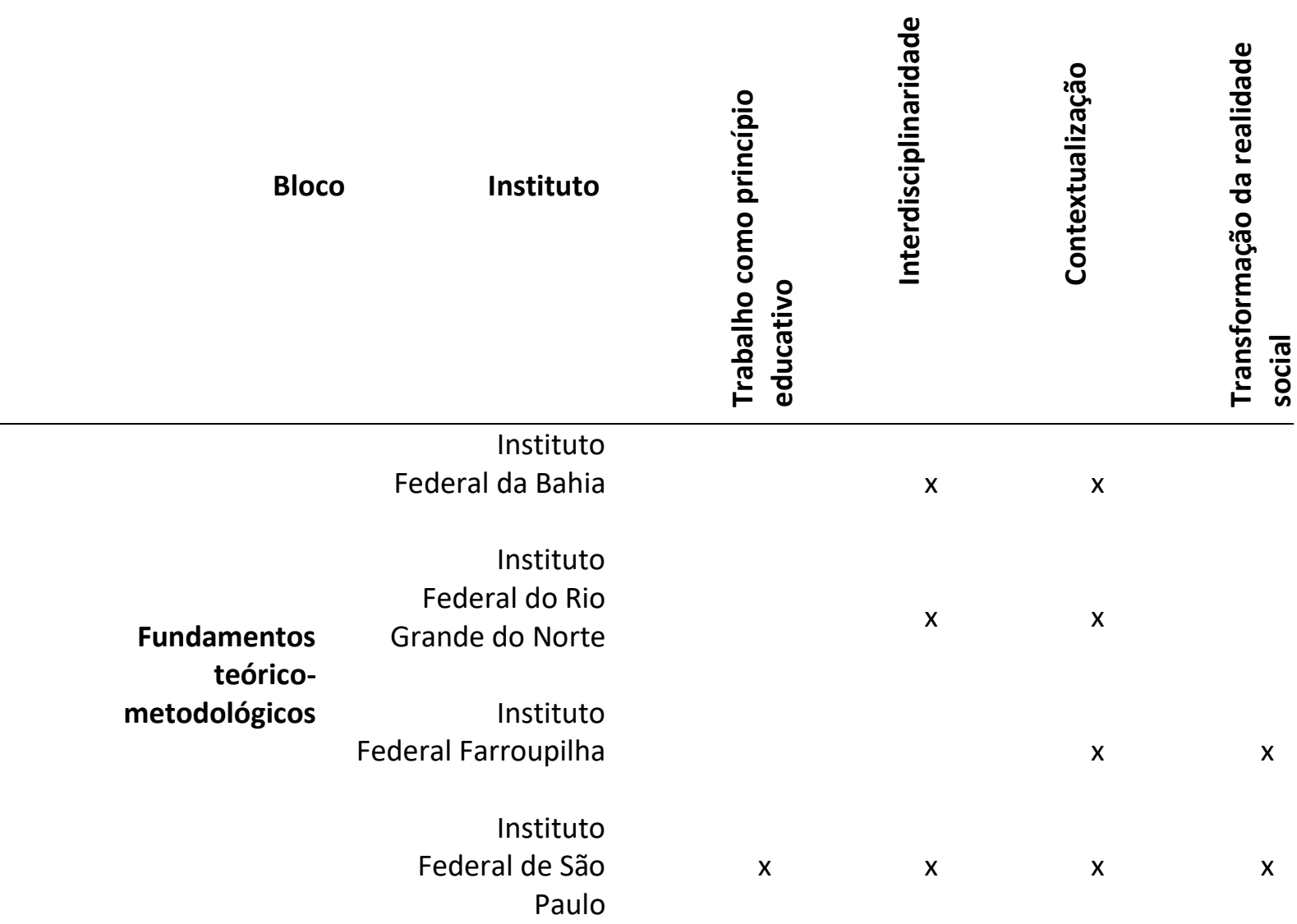




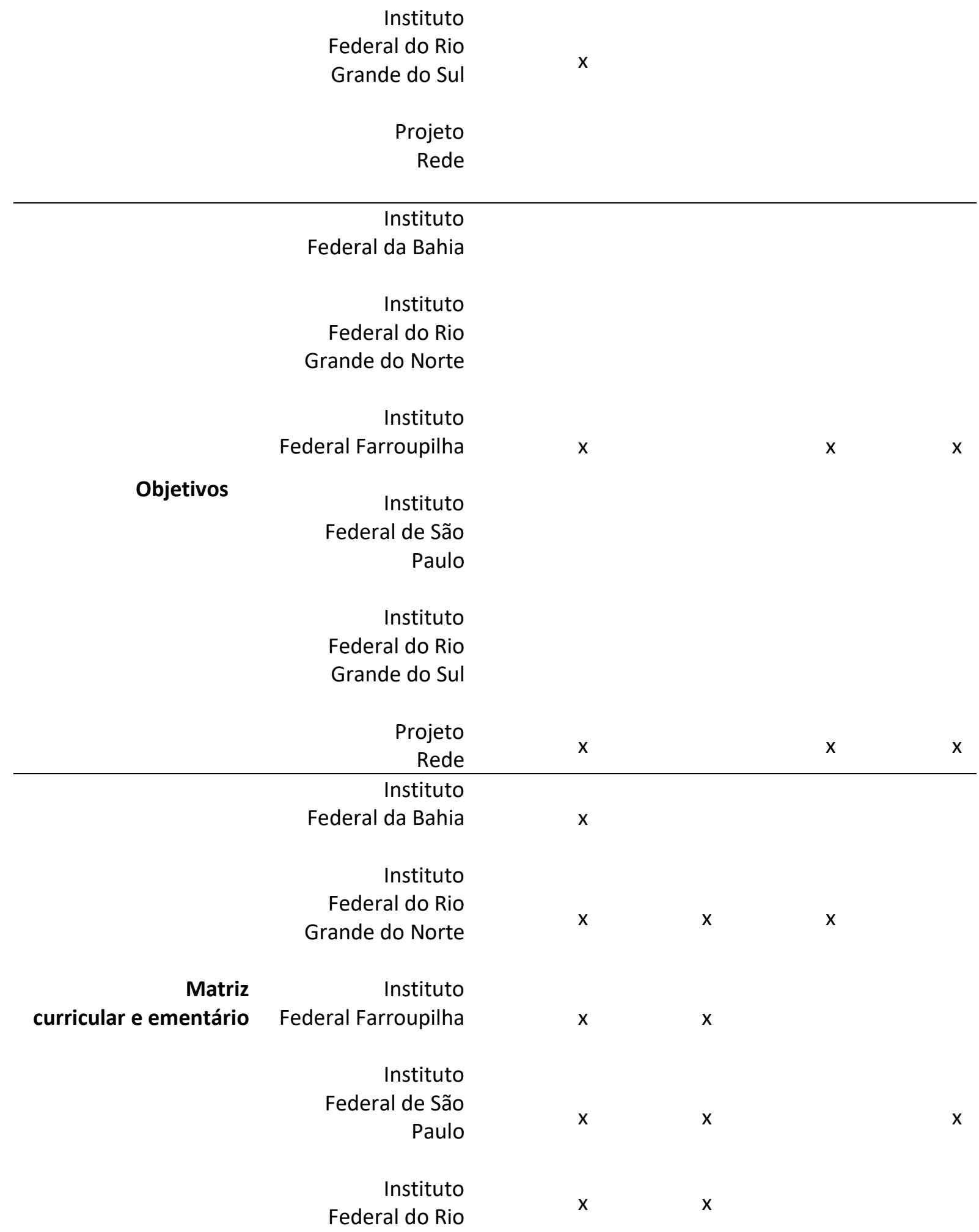


Grande do Sul

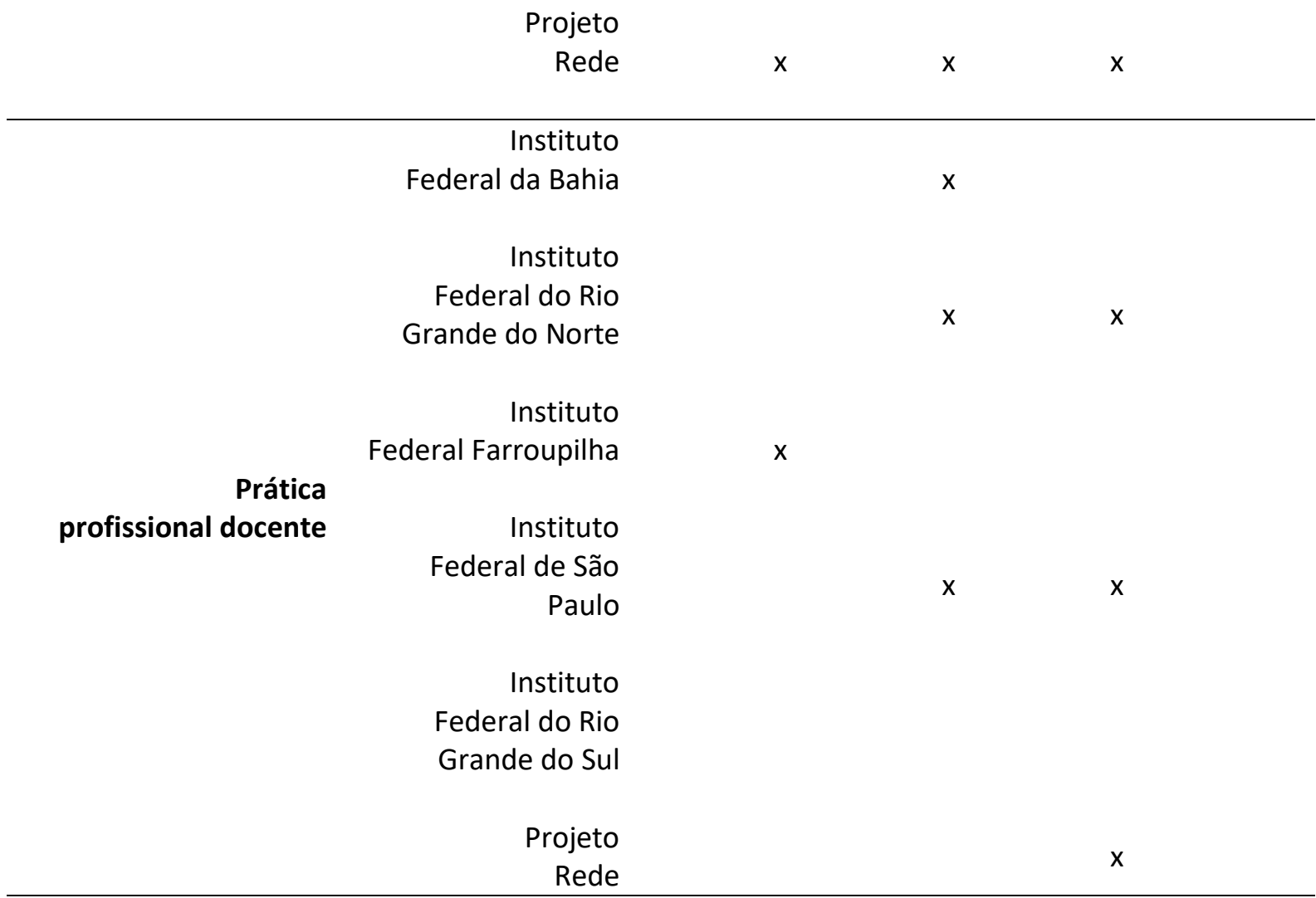

Fonte: Elaborado pelos autores

No que se refere à categoria interdisciplinaridade, identificamos claramente que nenhum dos objetivos elencados nos projetos são voltados para a formação de profissionais do ensino que trabalhem com proposta pedagógica interdisciplinar, mesmo este sendo o grupo mais citado. Tal postura é comprovada por Santomé (1998) quando diz que os cursos de licenciatura ainda são estruturados na perspectiva lineardisciplinar, reverberando nos processos educativos escolares e na sala de aula.

Ramos (2005) também fala que a interdisciplinaridade no ensino nasce a partir da necessidade de superação da infertilidade de posturas mais globais do conhecimento, acarretando excessiva compartimentação e falta de comunicação dos diversos campos científicos e, consequentemente, dos saberes escolares. De forma contrária, a integração destes saberes traria a unidade necessária entre as ciências e as disciplinas, atualmente refugiadas em seus próprios isolamentos, e promoveria o 
ensino integrador, fato este inexistente ou incipiente nos projetos, conforme quadro analisado.

Prosseguindo para a próxima categoria, a contextualização, a descontinuidade da abordagem desse item nos blocos de análise persiste. Quando esta é visualizada em uma parte dos textos, em outras, porém, percebemos a falta de alusões, sobretudo nos ementários, nos quais apenas dois institutos o referenciam. Este bloco de análise é extremamente importante, pois as ementas são as referências iniciais do planejamento de aulas dos docentes. O que está contido nelas é o que deve ser ensinado ou apresentado aos futuros professores.

O cotidiano, neste sentido, é o ponto de partida da atuação docente, quando se quer ensinar um determinado conteúdo. A teoria se junta a ele como complemento das abstrações teóricas dos saberes científicos. Ao trazemos a realidade do estudante para a sala de aula que trabalha com o currículo integrado, a meta é criar uma "íntima articulação dos conteúdos formativos com a realidade social e com os projetos políticos dos trabalhadores e de suas organizações sociais" (ARAÚJO; FRIGOTTO, 2015, p.69). Daí sua importância que, como visto, não se apresenta efetivamente nos projetos de cursos para docentes graduados não licenciados nos IF.

No que diz respeito à categoria transformação da realidade social, constatamos que as alusões feitas a elas nas propostas são limitadas e compõem o grupo com menor número de referências feitas. Os projetos do IFBA (2018) e IFRN (2016), por exemplo, não citam esta temática em nenhum dos blocos. Além disso, no bloco matriz curricular e ementário, só o projeto do IFSP (2018) cita a transformação social em uma das ementas, o que indica mais uma vez a falta de preocupação por parte dos proponentes dos PPC quanto a este tema. Freire diz que o ser humano consciente e crítico de sua realidade, deve reconhecer sua história e suas potenciais mudanças.

Acontece, porém, que toda a compreensão de algo corresponde, cedo ou tarde, uma ação. Captado um desafio, compreendido, admitidas as hipóteses de resposta, o homem age. A natureza da ação corresponde à natureza da compreensão. Se a compreensão é crítica, ou preponderantemente crítica, a ação também o será. Se é mágica a compreensão, mágica será a ação (FREIRE, 1997, p. 106).

Além disso, quando observamos o bloco prática profissional docente, ali também não há nenhuma citação sobre esta questão. Nenhuma das propostas traz em 
seu texto, neste item especificamente, referências sobre uma atuação docente nos IF que tenha como foco a transformação social da comunidade do estudante.

\section{Considerações finais}

Temos, por fim, que a formação de professores para EPT no Brasil segue atualmente perpetuando as diferenças históricas entre ensino propedêutico e profissionalizante, na medida em que negligencia uma formação docente qualificada para sua atuação na educação profissional e no ensino integrado. Em sua maioria, ao invés de cursos regulares de licenciatura, opta-se por cursos especiais ou emergenciais, na tentativa de cumprir as metas feitas pelo Plano Nacional de Educação para formação docente (OLIVEIRA; NOGUEIRA, 2016).

Acontece que a formação para docentes na Educação Profissional requer planejamentos e ações diferenciadas em virtude das especificidades da formação técnica, a exemplo da oferta, sobretudo nos IF, do ensino integrado que aqui neste trabalho consideramos não só como modalidade de ensino, mas também como concepção educacional alinhada à educação politécnica (ARAÚJO; FRIGOTTO, 2015). Porém, lidar com o ensino integrado, sobretudo na perspectiva aqui proposta, requer um docente alinhado a esta vertente de ensino já a partir de sua formação inicial, fato este que não tem ocorrido, como indicam nossas análises ainda preliminares.

Conforme discutimos, nos projetos analisados, os princípios elencados como necessários para uma formação docente que tenha como pressuposto o ensino integrado, não se aproximam, nas propostas pedagógicas daqueles cursos, dessa concepção educacional. Isto se verifica quando constatamos, separadamente, que, embora haja alusões em todo o escopo dos textos dos projetos aos princípios do ensino integrado nos blocos de análise que retornam a esta concepção educacional, no seu conjunto, as propostas não fazem estas referências, fato que pode inviabilizar, pelo menos nos projetos, a formação inicial dos docentes para atuarem com processos pedagógicos integradores e com o ensino integrado, uma vez que não se trabalha efetivamente com este tema em sua formação inicial nos cursos.

Destacamos, assim, a existência barreiras, já na formação inicial de professores da EPT, para implementação do ensino integrado, mesmo este sendo uma realidade nos IF que ofertam essa modalidade de ensino na educação profissional. 0 ensino 
médio deve se desenvolver sobre uma base unitária para todos, sendo condição necessária para fazer a travessia para uma nova realidade. Se o ensino integrado, portanto, significa uma nova postura educacional que objetiva eliminar a dualidade educacional presente hoje no Brasil entre ensino técnico e propedêudico, a formação dos professores torna-se um fator-chave para sua realização.

\section{Referências}

ANTUNES, R. Os sentidos do trabalho: ensaio sobre a afirmação e negação do trabalho. Boitempo: São Paulo, 1999.

ARAÚJO, R. M. L.; FRIGOTTO, G. Práticas Pedagógicas e ensino integrado. Revista Educação em Questão, Natal, v. 52, n. 38, p. 61-80, 2015. Disponível em: https://periodicos.ufrn.br/educacaoemquestao/article/viewFile/7956/5723 Acesso em: 23 ago. 2018.

BRASIL. Resolução CNE/CP no 1, de 18 de fevereiro de 2002. Institui Diretrizes Curriculares Nacionais para a Formação de Professores da Educação Básica, em nível superior, curso de licenciatura, de graduação plena. Disponível em: http://portal.mec.gov.br/cne/arquivos/pdf/CP012002.pdf Acesso em: 13 ago. 2018.

BRASIL. Resolução CNE/CP no 02, de 01 de julho de 2015. Define as Diretrizes Curriculares Nacionais para a formação inicial em nível superior (cursos de licenciatura, cursos de formação pedagógica para graduados e cursos de segunda licenciatura) e para a formação continuada. Disponível em: http://portal.mec.gov.br/docman/agosto-2017-pdf/70431-res-cne-cp-002-03072015pdf/file. Acesso em: 13 ago. 2018.

BRASIL. Lei no 11.892, de 29 de dezembro de 2008. Institui a Rede Federal de Educação Profissional, Científica e Tecnológica, cria os Institutos Federais de Educação, Ciência e Tecnologia, e dá outras providências. Brasília, DF: Presidência da República, 2008. Disponível em: http://www.planalto.gov.br/ccivil_03/_ato20072010/2008/lei/l11892.htm. Acesso em: 25 abr. 2019.

BRASIL. Decreto $\mathbf{n}^{\circ} \mathbf{2 . 2 0 8}$, de 17 de abril de 1997. Regulamenta o $\S 2 \circ$ do Art. 36 e os Arts. 39 a 42 da Lei no 9.394 de, 20 de dezembro de 1996. Brasília, DF: Presidência da República, 1997. Disponível em: http://www.planalto.gov.br/ccivil_03/decreto/D2208.htm Acesso em: 30 jul. 2018. 
BRASIL. Resolução no 3, de 21 de novembro de 2018. Atualiza as Diretrizes Curriculares Nacionais para o Ensino Médio. Disponível em: http://novoensinomedio.mec.gov.br/resources/downloads/pdf/dcnem.pdf Acesso em: 30 dez. 2018.

BRASIL. Lei $\mathbf{n}^{\circ}$ 9.394, de 20 de dezembro de 1996. Estabelece as diretrizes e bases da educação nacional. Brasília, Presidência da República. Disponível em: http://www.planalto.gov.br/ccivil_03/leis//9394.htm. Acesso em: 15 jan. 2019.

BRASIL. Lei $\mathbf{n}^{\circ} \mathbf{1 3 . 0 0 5}$, de 25 de junho de 2014. Aprova o Plano Nacional de Educação - PNE e dá outras providências. Brasília, Presidência da República. Disponível em: http://www.planalto.gov.br/ccivil_03/leis//9394.htm. Acesso em: 16 jan. 2019.

CARVALHO, O. F.; SOUZA, F. H. M. Formação do docente da educação profissional e tecnológica do Brasil: um diálogo com as faculdades e o curso de Pedagogia. Revista Educação e Sociedade, Campinas, n. 35, n. 128. jul./set. 2014. Disponível em: http://www.scielo.br/pdf/es/v35n128/0101-7330-es-35-128-00883.pdf. Acesso em: 27 mar. 2018.

CIAVATTA, Maria. Trabalho como princípio educativo. In: PEREIRA, Isabel Brasil; LIMA, Julio César França. (org.). Dicionário da Educação Profissional em Saúde. Rio de Janeiro: Escola Politécnica de Saúde Joaquim Venâncio, 2009. p. 408-415.

FREIRE, P. Educação como prática da liberdade. Rio de janeiro: Paz e Terra, 1997. FREIRE, P. Pedagogia do Oprimido. Rio de Janeiro: Paz e Terra, 2005.

FRIGOTTO, G. Concepções de mudança no mundo trabalho e no ensino médio. In: FRIGOTTO, G.; CIAVATTA, M.; RAMOS, M. (org.). Ensino médio integrado: concepção e contradições. São Paulo: Cortez. 2005.

GIL, A. C. Métodos e técnicas da Pesquisa Social. 6. ed. São Paulo, Atlas, 2014.

GRAMSCI, A. Os intelectuais e a organização da cultura. Rio de Janeiro: a civilização brasileira, 1982.

INSTITUTO NACIONAL DE ESTUDOS E PESQUISAS EDUCACIONAIS ANÍSIO TEIXEIRA. Sinopse Estatística da Educação Básica 2017. Brasília, INEP, 2018. Disponível em: https://portal.inep.gov.br/sinopse-estatistica-da-educacao-basica. Acesso em: 10 dez. 2018. 
MACHADO, L.R.S. Diferenciais inovadores na formação de professores para a educação profissional. Revista Brasileira da Educação Profissional e Tecnológica. Brasília, v. 1, n. 1, p. 08-22, 2008. https://doi.org/10.15628/rbept.2018. Disponível em: http://www2.ifrn.edu.br/ojs/index.php/RBEPT/index. Acesso em: 10 dez. 2018.

MOURA, D. H. A formação docente para educação Profissional e tecnológica. Revista Brasileira da Educação Profissional e Tecnológica, Brasília, v. 1, n. 1, p. 08-22, 2008. Disponível em: http://www2.ifrn.edu.br/ojs/index.php/RBEPT/index. Acesso em: 10 dez. 2018

OLIVEIRA, M.R.N.S; NOGUEIRA, C.G. A formação de professores para educação profissional e o Plano Nacional de Educação (PNE): quais as perspectivas?. Revista Holos, Natal, v. 06. n. 32, p. 145-15, 2016. Disponível em: file:///C:/Users/usuario/Downloads/4987-13746-1-PB.pdf. Acesso em: 27 mar. 2018.

RAMOS, M. Currículo integrado. In: PEREIRA, Isabel Brasil; LIMA, Júlio César França. Dicionário da educação profissional em saúde. Rio de Janeiro: EPSJV, 2009.

RAMOS, M. Possibilidades e desafios na organização do currículo integrado. In: FRIGOTTO, G.; CIAVATTA, M.; RAMOS, M. (org.). Ensino médio integrado: concepção e contradições. São Paulo: Cortez. 2005

SANTOS, T. A. De bacharel a professor: a construção dos saberes pedagógicos na educação profissional. 2016. 103 f. Dissertação (Mestrado em Educação) Universidade do Oeste Paulista, UNOESTE, Presidente Prudente, SP, 2016. Disponível em: http://bdtd.unoeste.br:8080/jspui/handle/jspui/967. Acesso em: 22 ago. 2018.

SANTOMÉ, J. T. Globalização e interdisciplinaridade: o currículo integrado. Porto Alegre: Arte Sul LTDA, 1998.

SAVIANI, D. Trabalho e educação: fundamentos ontológicos e históricos. Revista Brasileira de Educação, Campinas, v.c12, n.c32, p. 52-180, jan./abr. 2007. Disponível: http://www.scielo.br/pdf/rbedu/v12n34/a12v1234.pdf. Acesso em: 02/04/2018

RODRIGUES, I. S.; SOUZA, F. C. S. Percurso histórico da formação de professores para educação profissional no brasil (Séculos XX - XXI). Revista HISTEDBR On-line, Campinas, v.17, n.2 [72], p.621-638, abr./jun. 2017. Disponível em: https://periodicos.sbu.unicamp.br/ojs/index.php/histedbr/article/view/8644682. Acesso em: 20 maio 2018. 
YIN, R. K. Estudo de caso: planejamento e métodos. Porto Alegre, RS: Bookman, 2005.

Enviado em: 24/05/2019

Aprovado em: 21/01/2020 